Session 1463

\title{
Computer Aided Materials Selection for Design and Manufacturing
}

\author{
D. M. Pai, B. Kailasshankar, C. Adams and G. J. Filatovs \\ Center for Advanced Materials and Smart Structures \\ Department of Mechanical Engineering \\ North Carolina A\&T State University \\ Greensboro, NC 27411
}

\begin{abstract}
Machine design as taught in most machine design courses tends to focus mainly on considerations of geometry and stress analysis, with the selection of material and manufacturing processes and the specification of manufacturing tolerances becoming almost an afterthought. Although most engineering students are taught materials science as a fundamental science course, the curriculum downstream does not foster the incorporation of these principles into the systematic selection of the most appropriate material for a certain shape and function, or the criterion-based selection of the optimal manufacturing process. Tighter integration between the introductory materials courses and the downstream design and manufacturing courses is just part of the solution. With the advances in materials and manufacturing technology, a plethora of materials and processes has evolved. Undergraduate courses in design and manufacturing cannot provide detailed coverage of all materials and processes, and thus one has to harness the knowledge archiving and retrieval capabilities possible with today's information technology. The authors describe their experiences with a popular materials and process selection program (Cambridge Engineering Selector) that has been deployed in a junior level manufacturing processes class as well as a senior/graduate level aluminum design class. Students experience different aspects of the software, with the usage of its vast capabilities getting more sophisticated as they progress along the curriculum.
\end{abstract}

\section{Background}

The process of design necessitates a good understanding of the properties of materials as well as the manufacturing processes necessary to create a product out of these materials. Fundamentals of material behavior and of manufacturing processes are, in most engineering curricula, typically imparted in engineering science type courses early in the curriculum. The actual usage of this information in the design process is left to the capstone machine design projects and engineering design courses. There is a disconnect between the learning of the early years and the real-world product design work that follows. This is natural, because fundamental classes talk in generalities - materials, for example, are classified broadly as metals, ceramics, polymers and composites and their general structure, mechanical and physical properties are discussed. Likewise, manufacturing processes are broadly classified into forming, solidification, removal and joining. It is always somewhat of a shock for students to learn that the number of real-world materials available ${ }^{1}$ to them for engineering design range between 40,000 - 80,000 instead of the idealized four or five categories taught in class. Similarly, there are thousands of 
viable manufacturing processes; not just the four or five broad categories.

Secondly, engineering science classes rarely discuss materials or process costs. Machine design and economics lay increasing pressure on exacting materials with more precise properties and lower factor of safety. For example, a shaft currently made of medium carbon chromium molybdenum steel, can economically be substituted with manganese chromium steel (with no loss in mechanical properties) if the price of molybdenum goes up. As another example ${ }^{2}$, a titanium nitride coat on an HSS drill-bit can extend its life ten-fold between sharpenings, paying many times over for the added cost of the coating. This trend and the diversity of materials, both proprietary and generic, have made materials selection not just an art, but a complex web of intertwined property matches to meet the design requirements. There is no way to go but to use information technology for materials selection.

Manufacturing engineers in the field, too, are constantly being pressed to reduce costs - it is a good idea for students to be armed with some kind of knowledge of relative costs of materials and processes. The designer is now forced to become better aware of the manufacturing choices and their systematic selection ${ }^{3}$. Additionally, new process technologies have made obsolete the processes that they replace - for example, the increasing use of laser cutting for sheet metal part cutting. Further, manufacturing of discrete micro and smaller level products are being enabled by technologies such as nanotechnology and nanofabrication ${ }^{4}$.

\section{Approach}

While Computer-Aided Design and Manufacturing have existed for many years, there were few widely-available computer-based methods of material/process selection. Limited computing power in the past meant that the sheer number of materials and processes available could only be stored on mainframe computer. The desktop and laptop computers of the present decade easily match the computing power of supercomputers of the early 1980s. This has enabled materials selection to move from its status of being considered only at the start of the design process and then the selection being frozen into place. It is now possible to constantly change process and material based on economics. The emergence of the Internet and Web technology enable the use of live data to enable the lowest cost material to be chosen to provide comparable performance.

The first author obtained orientation training at an earlier ASEE Conference in the use of a commercially available package called Cambridge Engineering Selector ${ }^{5}-$ CES4. This was procured in Fall 2002 by the authors' university. The school license allows distribution of the software (which fits on $1 \mathrm{CD}$ and can be copied) to a specified number of students and faculty for academic use on their office or home computers for the duration of the license.

The authors worked with two classes that require the specification of materials and/or processes - Manufacturing Processes (MEEN 446, taught to juniors) and Aluminum-Based Product Design and Manufacture (MEEN 645, taught to seniors and graduate students). The manufacturing processes course, owing to time limitations, focuses principally on manufacturing with traditional materials such as metals and alloys. Other important materials like polymers, composites, ceramics and natural materials are covered only in brief reviews, and lead to the risk that a student will not be able to assimilate the importance of these other materials. The 
aluminum course requires students to obtain a better understanding of wrought and cast aluminum alloys - the use of the software proves to be a welcome supplement by adding depth regarding the specific applications and properties of numbered alloys.

CES4 divides the "universe" of materials into six major groups - metals, polymers, ceramics, composites, foams and natural materials. It provides physical properties like density, mechanical properties like tensile strength and yield strength, thermal properties like conductivity and coefficient of expansion, electrical properties like conductivity and resistivity, optical and corrosion properties and economic properties for the various groups of materials. It similarly divides the "universe" of processes into major groups. The information is hierarchically arranged and cross-linked to each other in relational database format.

CES 4 software for selection of materials is in several levels. Level 1 was introduced to the MEEN 446 students and Level 2 and 3 to MEEN 645 students - the latter introduces a professional - level materials selection system for senior/graduate students. Level 1 contains data for eighty widely-used materials. Students worked out material property attribute comparison charts in terms of modulus- density to look at low specific weight material and yield strength cost to determine the strongest material at lowest cost. Further, the students were able to easily generate bar and bubble charts based on specified properties for the designed machine component and provides a ranking of the materials. Once the materials are chosen, the manufacturing processes appropriate for the material are indicated. The students also did another project ${ }^{6}$ in which the material was already specified and more emphasis laid on selecting the right process, given the tolerances and cost constraints.

\section{Student evaluation of CES4 introduction module}

The students from the MEEN 446 worked on this module in groups of 3-4. A total of 19 students responded. The responses are summarized in Figures $1-3$.

Information received is relevant to the Manufacturing Processes

Course

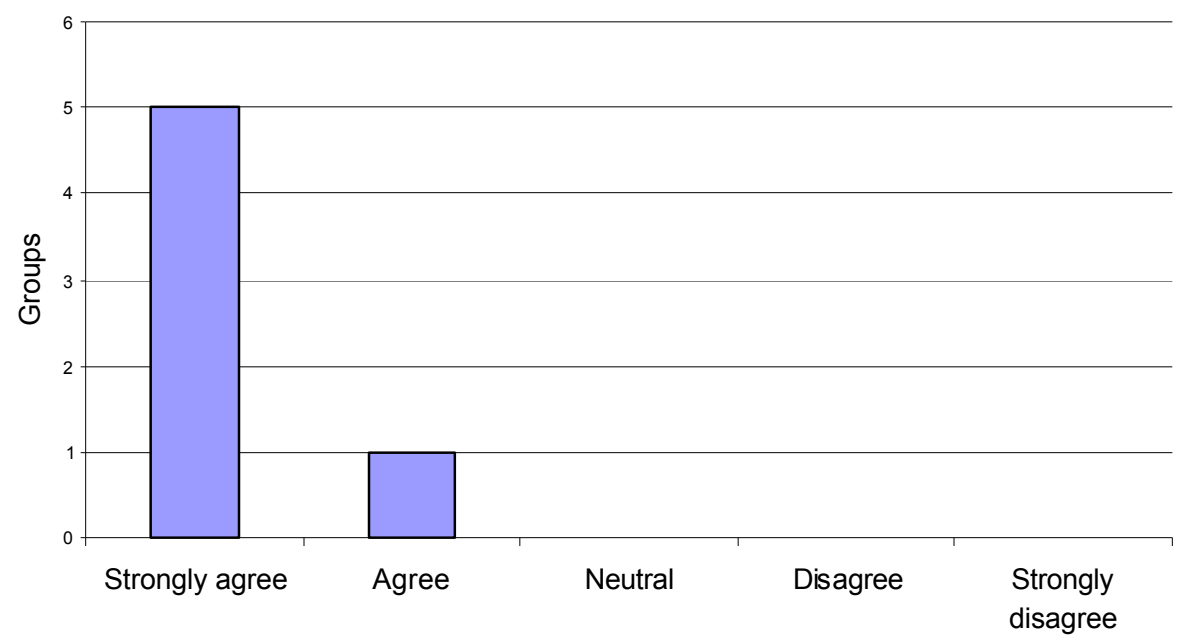


Figure 1 Relevance of software to Manufacturing Processes course

So $t$ tware is re levant $t o$ ot her courses in cur riculum

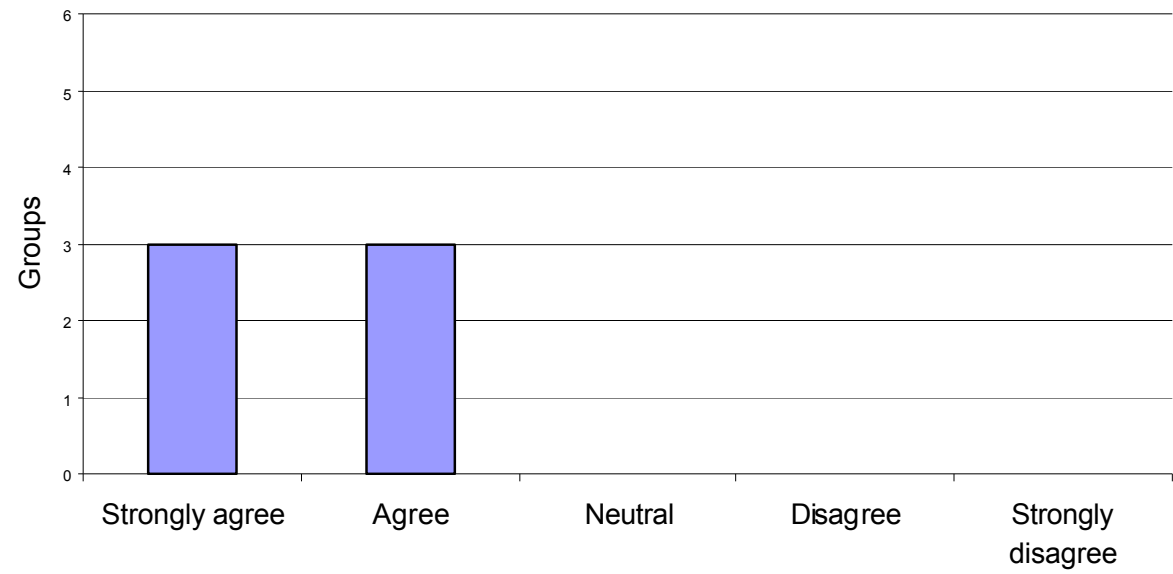

Figure 2 Relevance to other courses in curriculum

I would like to participate in more of the se learning modules

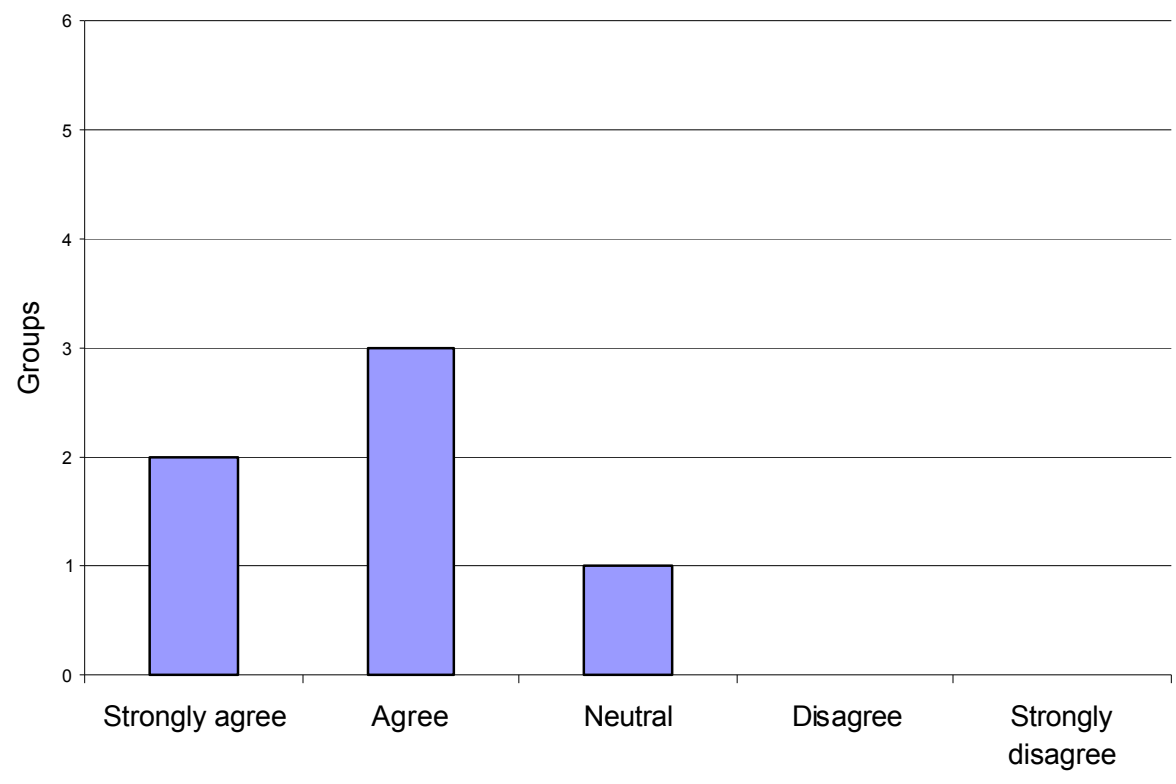

Figure 3 Interest in future modules

Students felt that this introduction will be useful for them in other subject areas including:

- Machine Design

- Strength of materials

- Heat Transfer

- Composites 
Students felt that they could use this information in a variety of ways like

- Determine machining processes

- Selecting materials for specific processes

\section{Students comments}

- Liked the abundance of information in the software

- Information about materials looked dependable and not like a manufacturer commercial

- Learned new software applicable to engineering

- Applied information learned in the materials science course

\section{Conclusions}

The software makes the students aware of the range of materials under consideration. This is likely to give the students a better understanding of the materials as the result is based on the properties required for the machine component design. CES 4 software is not intended as a complete solution provider, because the database does not provide design-approved properties. It is more a teaching tool for students to appreciate the relative importance of the diverse materials. Commercial designs can be done with the same user interface but by attaching it to a commercial standard database such as the MIL-Handbook.

Given the conflicting demands of time and practicality, the availability of a materials and process database and selection tool will greatly facilitate the student's ability to implement classroom fundamentals in a meaningful way in their class design projects as they prepare to transition their skills and knowledge but limited experience into the workforce. The software enables students to explore a far broader spectrum of materials and processes than physically possible to even enumerate in class. The challenge, of course, lies in highlighting to the students the care that must be exercised in the judicious use of selection criteria and performance indices. The untutored use of student-friendly software risks giving the student a false impression of the scope and depth of current industrial practice, ostensibly making it easy to obtaining numerous parameters and statistics without understanding the implicit assumptions and limits of applicability. In teaching, there is a balance between the amount of fundamentality of principles, and the extent of software involvement. Both careful selection of software and major accommodation of topics are important for maintaining this balance.

\section{References}

[1.] Ashby, M. F., 1999, "Materials Selection in Mechanical Design,” $2^{\text {nd }}$ edition, Butterworth Heinemann, London, England.

[2.] Hurst, K., 1999, “Engineering Design Principles,” Arnold, London, England.

[3.] Swift, K. G. and Booker, J. D., 1997, "Process Selection - From Design to Manufacture," Arnold, London, England.

[4.] Kalpakjian, S., and Schmid, S. R., 2003, "Manufacturing Processes for Engineering Materials," Fourth edition, Prentice Hall, Upper Saddle River, NJ.

[5.] Granta Design Limited, 2002, “CES4: Cambridge Engin eering Selector v4,” Cambridge, England. 
[6.] Ashby, M. F. and Cebon, D., 1996, "Case Studies in Materials Selection," Granta Design Limited, Cambridge, England.

\section{Biographies}

DEVDAS M. PAI is Associate Professor of Mechanical Engineering at NC A\&T State University. He received his M.S. and Ph.D. from Arizona State University. He teaches manufacturing processes and machine design. A registered Professional Engineer in North Carolina, he serves on the Professional Licensure Committees of the NCEES and SME and is active in the Manufacturing Division of ASEE and the Materials Division of ASME.

BALA KAILASSHANKAR is a PhD student and Graduate Teaching Assistant in the Department of Mechanical Engineering. He received the B. Tech. Degree in Metallurgy from the Indian Institute of Technology and the MS in Mechanical Engineering from NC A\&T State University. He has over 20 years of research, development and manufacturing experience in the tribology and coatings industry.

CHAD E. ADAMS is currently a senior dual-degree student pursuing the BSME at NC A\&T State University and a BS in Mathematics with Physics minor at Morehouse College in Atlanta, GA. He has had summer intern experience with the Boeing Company in Houston, TX, doing thermal analysis for the International Space Station. He is active in NSBE, ASME and a member of the Golden Key Society.

G. JURI FILATOVS is a Professor of Mechanical Engineering at NC A\&T State University. He received his Ph.D. from the University of Missouri-Rolla. He has worked for McDonnell Aircraft and the US Bureau of Mines. His research is in the area of materials and their properties. He teaches materials science and the capstone design courses in mechanical engineering. 